\title{
Medindo a interatividade em um ambiente de autoria hipermídia: qualificando processos de inclusão digital
}

\section{Measuring the interactivity in an environment of authoring hypermedia: qualifying procedures for digital inclusion}

\author{
Suellen Spinello ${ }^{1}$ \\ Adriano Canabarro Teixeira ${ }^{2}$ \\ ${ }^{1}$ Curso de Ciência da Computação - Universidade de Passo Fundo (UPF) \\ ${ }^{2}$ Mestrado em Educação - Universidade de Passo Fundo (UPF) \\ \{suellen, teixeira\}@upf.br
}

Resumo. Há uma crescente transformação ocorrendo na sociedade contemporânea devido ao advento das tecnologias de rede, impulsionando processos interativos e hipermídia, em que os usuários são chamados a participar, interagir e colaborar. Dentro deste contexto, este artigo trata do processo de desenvolvimento de um mecanismo de acompanhamento dos níveis de interatividade do ambiente de autoria hipermídia denominado criAtivo.

Palavras-chave: Interatividade, Cibercultura, Inclusão Digital, Hipermídia.

Abstract. There is a growing transformation occurring inside the contemporary society due to the advent of the network technologies which is boosting interactive and hypermedia processes, where users need to participate, interact and collaborate. On this context, the present article treat the process of developing a mechanism for monitoring the levels of interactivity of the environment of authoring hypermedia, denominated creAtive.

Keywords: Interactivity, Cyberculture, Digital Inclusion, Network Logic, Hypermedia.

\section{Introdução}

A sociedade atual vive a constante evolução de seus princípios e fundamentos, sendo que uma das mais significativas aconteceu na área das tecnologias de informação e comunicação, que geralmente se caracterizam pela comunicação unidirecional, não contemplando as perspectivas reticulares das tecnologias digitais de rede, que têm transformado a dinâmica social contemporânea.

As estruturas técnicas de rede permitem implementar novas e complexas formas de interação social. Ao referir-se às redes, Castells as define como um "conjunto de nós interconectados", cujas principais características são a "flexibilidade e adaptabilidade" (2003, p. 7). Essa dinâmica das redes acaba, muitas vezes, rompendo com a lógica de 
2

recepção de informações instituída, pois não basta aos indivíduos serem nós presentes, mas inativos, na rede, eles necessitam vivenciar processos de interação, experienciando momentos de autoria numa perspectiva reticular, especialmente em se reconhecendo que processos baseados na interatividade são fundamentais para a construção do conhecimento.

Neste sentido, o objetivo deste trabalho consiste no relato do processo de implementação de um mecanismo que tenha condições de monitorar a interatividade que as comunidades do ambiente hipermídia de autoria colaborativa - criAtivo ${ }^{1}$, apresentam. Destaca-se que o elemento principal deste trabalho não é a simples implementação do mecanismo de monitoramento, mas o processo de desenvolvimento deste a partir de conceitos teóricos, buscando caracterizar de forma qualitativa a interatividade presente nos projetos do ambiente.

Para tanto, optou-se pela definição de graus de interatividade, baseados nos binômios propostos por Silva (2002), cuja função é atribuir valores às ações e aos movimentos interativos dos membros das comunidades do criAtivo.

Tal demanda nasceu da necessidade de se medir qualitativamente o nível de interatividade entre os autores e co-autores dos projetos desenvolvidos no ambiente, informação fundamental para que se possam perceber os movimentos interativos e reticulares fundamentais ao processo de construção do conhecimento que o criAtivo, em sua concepção, buscava sustentar.

\section{Interatividade na Cibercultura}

$\mathrm{Na}$ sociedade contemporânea, grandes transformações e evoluções vêm ocorrendo impulsionadas pelas tecnologias digitais de rede, definindo um fenômeno que podemos chamar de cibercultura. Compreender o seu significado é de suma importância, pois na atualidade inúmeros fatores econômicos, sociais, políticos e artísticos, dentre outros, estão em constante reconfiguração devido ao avanço tecnológico.

A cibercultura, definida como "a cultura contemporânea marcada pelas tecnologias digitais" (Lemos, 2003, p.11) surgiu da fusão das tecnologias com o cotidiano, isto é, estamos vivendo em plena cibercultura. Não se trata de algo que vai chegar, e, sim, da nossa realidade, como os celulares, o voto eletrônico, pages, palms, notebooks e o crescente uso da internet como meio de comunicação e aprendizado.

As características de tempo e espaço também são transformadas na cibercultura, pois há uma "nova conjuntura espaço-temporal marcada pelas tecnologias digitais" (p. 13), onde tempo e espaço estão desmaterializados - independente de nossa localização geográfica podemos agir em qualquer outro lugar, emitindo e recebendo informações em tempo real. Outra transformação, que segundo Lemos está relaciona a esta, é a evolução do computador pessoal para o computador conectado, e este para o computador conectado móvel, em que as características das redes são fundamentais - a "rede é tudo e tudo esta em rede" (p. 14).

Diante desta conexão instituída, outros processos são deflagrados, como é o caso da exclusão digital: nem todos possuem acesso às tecnologias de rede. Uma apropriação 
3

social e horizontal das tecnologias é fundamental para que os indivíduos possam fazer parte da cibercultura como protagonistas.

\subsection{Inclusão digital na sociedade contemporânea}

Para que se possa entender a inclusão digital na sociedade contemporânea, tornase imprescindível ultrapassar a questão de que incluir é proporcionar apenas o acesso às tecnologias de rede, mas, sim, deve-se considerar a forma como os indivíduos se apropriam destas tecnologias, uma vez que a apropriação necessita se dar de maneira criativa, dinâmica e interativa.

Entretanto, questões de simples acesso às tecnologias não devem ser inteiramente descartadas, sendo que todas as formas de acesso dependem de subsídios tecnológicos, o que dificulta ou até mesmo impossibilita que muitos indivíduos possam ser nós presentes nas redes, fazendo com que a busca pela democratização de acesso às tecnologias se torne o passo inicial, e muitas vezes o principal, no que se relaciona à inclusão digital.

Outro fator importante no contexto da inclusão digital é a crescente virtualização da sociedade em que vivemos, fazendo com que as pessoas que não possuem acesso ao ciberespaço, ou até mesmo que não o reconhecem como um espaço de comunicação e de exercício da cidadania, tornem-se excluídas dessa sociedade. Assim, percebe-se que a exclusão digital não está relacionada apenas ao poder aquisitivo dos indivíduos, e sim à postura assumida perante esta nova estrutura tecnológica.

É importante destacar que os indivíduos necessitam vivenciar uma cultura de rede, que permita "uma apropriação diferenciada, pautada na criticidade, na criatividade e na autoria" (Teixeira, 2005, p.30), assumindo atitudes pró-ativas, em um sentido de interação e participação, para que as potencialidades das tecnologias de rede possam ser reconhecidas e utilizadas de forma plena.

\subsection{Fundamentos da Interatividade}

O termo interatividade tem sido muito utilizado na atualidade, e resume de certa forma, tudo o que de diferente é atribuído às novas tecnologias de rede. A interatividade se apresenta como um elemento fundamental para o estabelecimento de processos comunicacionais e de aprendizagem que possam ir ao encontro da dinâmica da lógica das redes presente na Cibercultura.

A interatividade vem se destacando cada vez mais como a modalidade comunicacional da cibercultura, pois o modo de comunicação interativo vem transformando e reconfigurando a tradicional forma de comunicação de massa, principalmente pelo ciberespaço, possibilitando o "rompimento com o reinado da mídia de massa baseada na transmissão" e permitindo "ao indivíduo teleintra-interante a comunicação personalizada, operativa e colaborativa em rede hipertextual" (Silva, 2005, p. 193), hipermidial e interativa.

A interatividade é um elemento marcante da dinâmica social contemporânea, e vem sendo entendida como "a intervenção dos usuários no conteúdo de mensagens e do produto e a bidirecionalidade entre emissão e recepção, entre interlocutores humanos, 
4

entre usuários e máquinas, entre usuários e serviços" (Silva, 2002, p.92), sendo fundamental para o estabelecimento de processos de comunicação e aprendizagem.

Estas novas tecnologias interativas tendem a proporcionar aos indivíduos a "participação, a interação, a bidirecionalidade e a multiplicidade de recepção", pois as mesmas têm características que proporcionam e "ampliam a sensorialidade e rompem com a linearidade" no sentido de abolir com a separação entre "emissão/recepção" (p. 13), em um sentido onde cada indivíduo pode experimentar não a disjunção entre emissão e recepção, mas a experiência da co-autoria.

\subsection{Binômios da Interatividade}

Uma vez que a proposta deste trabalho é baseada na interatividade e seus fundamentos, iremos trabalhar os binômios da interatividade, que se destacam como uma forma de compreender/medir/acompanhar a interatividade segundo alguns princípios básicos. Silva classifica os binômios em três: participação-intervenção, bidirecionalidadehibridação e potencialidade-permutabilidade, que, em seu entender, são uma tentativa de sistematizar o mapeamento de especificidades e singularidades dentro da interatividade. (2002, p.100).

Para alguns, a participação-intervenção do usuário no funcionamento de um sistema ou equipamento é o aspecto mais evidente na concepção de interatividade, pois pressupõe a participação. Entretanto, para o autor, esse aspecto parece o mais enganoso no mercado ou na indústria da interatividade, pois a comunicação interativa fundada na participação não é apenas emissão, mas também produção conjunta da emissão e recepção.

O binômio bidirecionalidade-hibridação trata do modo como a comunicação é arquitetada dentro do espaço, tendo em vista a alternância entre ações de emissão e recepção. Neste binômio, só existe comunicação a partir do momento em que não há mais sujeitos que assumem papéis fixos de emissores ou receptores, mas sim quando o emissor é potencialmente um receptor e todo receptor é potencialmente um emissor.

Por fim, o computador, especialmente os conectados em rede, pode ser considerado interativo pela sua liberdade de navegação aleatória, que é garantida pela disposição tecnológica. Esta arquitetura é que permite ao usuário atitudes permutatórias e potenciais, onde se supõe multiplicidade e pluralidade como espaço aberto para conexões possíveis e aleatórias.

Destacamos que, no ciberespaço, os ambientes interativos tendem a se popularizar e a oferecer uma gama cada vez maior de ferramentas que suportem processos interativos. Entretanto, é preciso que se reconheça que a existência de suporte à interatividade não garante movimentos interativos em um ambiente, uma vez que demanda uma mudança de postura dos usuários que participam daquela comunidade.

Assim, o desenvolvimento de mecanismos que acompanhem os níveis de interatividade pode auxiliar significativamente na tomada de decisão dos tutores humanos e na automatização de procedimentos específicos e automáticos com vistas à promoção da interação. 


\subsection{Atribuições de graus de interatividade aos binômios}

A atribuição de graus de interatividade aos binômios é uma forma de tentar qualificar, de um modo mais refinado, cada fundamento dos binômios destacados por Silva. Neste sentido, para a implementação do mecanismo de monitoramento, cada binômio recebeu graus equivalentes às suas características. Estes graus possuem pesos de 1 à 4, onde 1 representa uma interação de relevância mínima e, 4, a máxima dentro de cada binômio, como exemplifica o fragmento da Tabela 1 .

Para a aplicação destes conceitos e testagem do mecanismo, foi utilizado o criAtivo, tendo como elementos de monitoração as ações relacionadas às comunidades. Sendo assim, cada ação dentro do ambiente tem um valor específico em relação às designações dos graus dos binômios destacados anteriormente.

A tabela abaixo demonstra apenas o primeiro binômio da interatividade com seus respectivos graus e características, identificando as ações respectivas a cada um dos graus em relação às comunidades do criAtivo.

Tabela 1. Demonstração dos níveis de interatividade dos binômios e as ações que serão monitoradas.

\begin{tabular}{|c|c|c|c|}
\hline Binômio & Grau & Característica & $\begin{array}{l}\text { Ações/características/ferramentas } \\
\text { no/do criAtivo }\end{array}$ \\
\hline \multirow{4}{*}{$\begin{array}{l}\text { Participação } \\
- \\
\text { Intervenção: } \\
\text { participação } \\
\text { do indivíduo } \\
\text { como emissor } \\
\text { e receptor, } \\
\text { participando e } \\
\text { interagindo } \\
\text { com e através } \\
\text { do ambiente. }\end{array}$} & $\begin{array}{l}1 \text { Tecnológica } \\
\text { (disposição de } \\
\text { ferramentas } \\
\text { comunicacionais) }\end{array}$ & $\begin{array}{l}\text { A quantidade de } \\
\text { ferramentas/espaços de } \\
\text { interação que o ambiente } \\
\text { proporciona; }\end{array}$ & $\begin{array}{l}\text { Editor colaborativo, fórum de discussão } \\
\text { do projeto, sala de bate-papo, fórum } \\
\text { geral, e-mail; }\end{array}$ \\
\hline & $\begin{array}{l}2 \text { Política } \\
\text { (Ações de } \\
\text { comunicação) }\end{array}$ & $\begin{array}{l}\text { Possibilidade de controle e } \\
\text { gestão do } \\
\text { ambiente/comunidade/ } \\
\text { projeto }\end{array}$ & $\begin{array}{l}\text { Criar um projeto; } \\
\text { Criar um item no fórum; } \\
\text { Votar a exclusão de um momento no } \\
\text { projeto; }\end{array}$ \\
\hline & $\begin{array}{l}3 \text { Sensorial } \\
\text { (Disposição de } \\
\text { ferramentas de co- } \\
\text { autoria) }\end{array}$ & $\begin{array}{l}\text { Necessidade de sentir-se } \\
\text { participante da ação que } \\
\text { está acontecendo. }\end{array}$ & $\begin{array}{l}\text { Ser respondido em um item no fórum, e- } \\
\text { mail ou chat; Interagir e colaborar com } \\
\text { comunidades, projetos, itens de discussão } \\
\text { no fórum; } \\
\text { Quando a ordem dos autores muda no } \\
\text { proieto. }\end{array}$ \\
\hline & $\begin{array}{l}4 \text { Comunicacional } \\
\text { (Ações de co- } \\
\text { autoria) }\end{array}$ & $\begin{array}{l}\text { Mudança que ocorre com a } \\
\text { emergência da modalidade } \\
\text { interativa de comunicação. }\end{array}$ & $\begin{array}{l}\text { Quando obtém resposta de um item } \\
\text { criado no fórum; } \\
\text { Quando é convidado para um chat; } \\
\text { Quando recebe uma resposta de e-mail; }\end{array}$ \\
\hline
\end{tabular}

A partir desta tabela, é possível visualizar como cada grau foi trabalhado dentro do criAtivo em relação às ações ou elementos que são monitorados. Neste sentido, apresenta-se a forma como se efetuou este monitoramento.

\section{Medindo a interatividade no criAtivo}

O monitoramento das atividades nas comunidades do criAtivo foi implementado de uma forma através da qual o indivíduo não visualize que suas ações estão sendo monitoradas. Cada ação realizada ou elemento do ambiente que for utilizado pelo autor gera a atualização automática de uma tabela, onde é registrada a ação que o usuário efetuou referente aos graus de interatividade de cada binômio.

Em uma situação hipotética, quando o usuário criar um tópico no fórum de discussão da comunidade, o mesmo estará sendo acompanhado, gerando uma série de 
6

atualizações nas tabelas de controle, a partir da análise desta ação de acordo com o conceito do primeiro binômio (participação-intervenção) e, dentro deste, em qual perspectiva esta ação se encontra. No caso exemplificado, a ação praticada está relacionada à perspectiva política, referente às ações de comunicação, computando, assim, o grau de relevância 2 a este binômio.

\subsection{Detalhamento do procedimento de monitoração da interatividade do criAtivo}

Para o desenvolvimento do procedimento de monitoração, criaram-se as seguintes tabelas: binômios, ações, monitorações e gráfico.

A tabela de binômios armazena o código do binômio e o seu nome correspondente. Como se trabalhou com os três binômios da interatividade, ela armazena o nome dos mesmos. A tabela de ações é composta pelo código do binômio, pelo grau específico, pelo código da ação e pelo nome da ação que será monitorada nas comunidades do criAtivo. Estas tabelas possuem valores fixos, servindo para o processo de monitoramento.

A tabela de monitoração é a que recebe os valores advindos das interações dos usuários no ambiente, a saber: o código do participante que efetuou a ação, o código da ação praticada, o código da comunidade em que a ação foi monitorada, seu grau equivalente e a data e a hora em que ação foi efetuada.

A atualização da tabela Gráfico é feita paralelamente à atualização da tabela de monitoração, gravando sempre o somatório dos graus praticados em cada binômio, sendo que esta tabela recebe o código da comunidade, o código do projeto e os valores dos somatórios dos binômios 1, 2 e 3 .

No criAtivo, cada ação prevista foi estudada de forma com que pudesse ser monitorada. Para tanto, todo o código fonte do ambiente foi estudado, para que cada ação fosse monitorada da melhor forma, e para que cada ação prevista na monitoração fosse efetivamente implementada.

Para o processo de atualização das tabelas, foi desenvolvida uma função de monitoramento que recebe o código do participante, a ação, o grau referente a cada ação monitorada, o código da comunidade e do projeto em que se está praticando a ação. Esta função é acionada toda vez que é efetuada uma ação que está sendo monitorada e que equivale aos graus definidos.

Recebidos estes valores, a função irá armazená-los no banco de dados, juntamente com a data e a hora em que a ação foi praticada. Estes valores serão armazenados na tabela de monitoração para possíveis consultas, pois a partir dela é possível identificar quais foram as ações mais praticadas e quais os usuários que mais interagiram nas comunidades.

Além de armazenar nesta tabela, a função também armazena o código da comunidade, o código do projeto e o valor da ação realizada na tabela gráfico, sendo que cada valor é separado de acordo com cada binômio da interatividade.

Estes valores são armazenados seguindo os seguintes princípios. É verificado, antes do seu armazenamento, se os códigos da comunidade e do projeto não estão 
armazenados na tabela gráfico. Se não estiverem, insere-se o novo valor no banco, caso contrário, o valor é atualizado. A divisão de valores está relacionada aos dados já cadastrados na tabela de ações, na qual estão descritas todas as ações que serão monitoradas. As ações que representam o primeiro binômio possuem códigos que vão de 1 a 21, as referentes ao segundo binômio, de 22 a 40, e as do terceiro binômio tem codificação de 41 a 59.

Além de armazenar pelo código da comunidade e do projeto, também existe a necessidade de se efetuar o armazenamento apenas pelo código da comunidade, uma vez que existem alguns recursos oferecidos pelo ambiente, como os de comunicação por exemplo, que não estão disponíveis a projetos específicos, e sim às comunidades. Entretanto, representam movimentações interativas.

Para solucionar esta situação e manter o registro destas ações, possibilitando gerar o gráfico da interatividade das comunidades, todas as ações praticadas e monitoradas precisam estar armazenadas. Para que isto seja possível, quando os autores do ambiente utilizam estes recursos, é gravada uma nova linha no banco de dados, onde se busca o código da comunidade e se insere automaticamente um valor fixo de projeto (valor 100). O valor da ação é armazenado seguindo os mesmos critérios já exemplificados.

Destacamos a importância de armazenarmos os valores da monitoração também pelo código do projeto, para que possamos identificar o quanto de interatividade cada projeto obteve na comunidade, pois alguns projetos podem possuir um grau mais elevado de interatividade do que outro. Esta opção foi feita para posteriores ações de interação específicas aos projetos.

\subsection{Detalhamento da geração do gráfico dos níveis de interatividade de cada comunidade}

Os níveis de interatividade das comunidades do criAtivo é apresentada para os usuários através de um gráfico. Cada ação que for praticada dentro de uma comunidade atualizará automaticamente o gráfico da interatividade.

No momento em que o gráfico for gerado, recebe previamente alguns valores fixos que representam a existência de elementos e a possibilidade de efetuar ações e atividades dentro do ambiente. O primeiro binômio receberá automaticamente, antes de qualquer outro valor, o valor 5; o segundo binômio receberá 25, e o terceiro binômio, 16.

A figura 1 representa como este gráfico será visualizado dentro do criAtivo. Para exibir o gráfico da interatividade, é necessário clicar no link gráfico destacado na Figura 1, detalhe A, a partir do qual se abrirá uma nova tela com o gráfico referente à comunidade que se está acessando. Uma vez que o gráfico é gerado por comunidades, cada uma terá seu gráfico de interatividade específico.

O gráfico exemplo representa o somatório dos graus de interatividade que cada binômio obteve dentro da comunidade. Todas as ações que representam processos interativos foram monitoradas para a sua geração. No exemplo da figura 1, a 
comunidade 13 obteve o grau 7 de interatividade no binômio 1, 37 no binômio 2 e 26 no binômio 3.

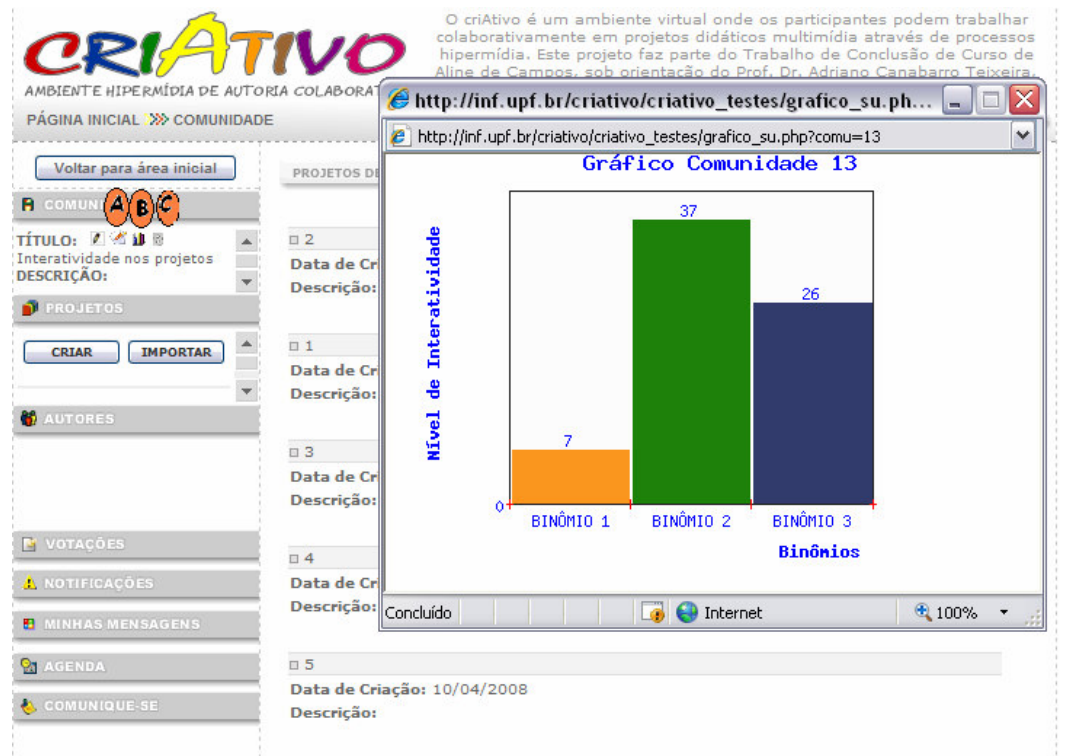

Figura 1 - Tela demonstrativa do gráfico da interatividade da comunidade $X$

Ao lado do link do gráfico encontra-se outro link (Figura 1, detalhe C) através do qual é possível ter acesso a um pequeno texto explicativo a respeito de cada binômio da interatividade, para que os usuários que estão acessando este gráfico possam entender o porquê da divisão destes valores, e qual a lógica que cada um segue. Desta forma, definiram-se os seguintes textos:

Binômio 1: Este binômio está relacionado efetivamente à participação dos usuários no criAtivo, com e através do ambiente pelas ferramentas de comunicação e de desenvolvimento que podem proporcionar integração e sustentar negociações entre os participantes, como, por exemplo, a leitura do fórum.

Binômio 2: O Binômio 2 se refere à alternância entre recepção e emissão de informação e conhecimento por parte dos autores, quando todos se tornam ao mesmo tempo potenciais produtores e receptores nas comunidades do criAtivo, como, por exemplo, quando um usuário participa interativamente do fórum de discussão da comunidade.

Binômio 3: Este binômio está relacionado às atitudes de co-autoria praticadas pelos usuários nos projetos das comunidades do criAtivo, em que cada usuário interage com os projetos já criados e, ao mesmo tempo, cria novos projetos para que os outros usuários também possam participar e interagir.

Para que se possa visualizar quais ações foram monitoradas e praticadas dentro de cada comunidade, existe um link na comunidade que permite que seja visualizada uma tabela em que são demonstradas a hora, a data, a ação praticada e qual o autor que praticou a ação (Figura 1, detalhe B). A visualização desta tabela permite identificar quais autores estão interagindo com a comunidade e quais ações estão sendo praticadas dentro da comunidade. Destaca-se também que estes dados, uma vez armazenados, podem servir a inúmeras análises acerca da participação dos autores dos projetos. 


\subsection{Promovendo a interação entre os usuários da comunidade}

Para os usuários que utilizam o criAtivo, apenas demonstrar o gráfico da interatividade não representará ou estimulará a interatividade entre os participantes e o ambiente. Assim, sentiu-se a necessidade de se criar mecanismos de fomento à interação, disparados a partir da monitoração das comunidades.

Neste sentido, embora extrapole os objetivos do trabalho, com base nos resultados finais advindos da monitoração das comunidades do criAtivo, desenvolveramse formas de interação automatizadas do ambiente junto ao usuário, de forma que os resultados gravados possam gerar ações de fomento à interatividade.

Sendo assim, a forma de interação realizada se dá basicamente através de e-mails, que são enviados automaticamente para os participantes das comunidades a partir do nível de interatividade praticado para cada binômio. Para o primeiro binômio da interatividade, que representa a participação-intervenção dos usuários no criAtivo, será enviado um e-mail para os participantes de comunidade quando o nível de interatividade no binômio 1 for menor que 5, valor base e fixo para este binômio.

Neste e-mail, abaixo transcrito, será divulgado aos participantes quais as possibilidades, ferramentas e ações de participação e interatividade que o ambiente proporciona, de uma forma onde cada indivíduo possa conhecer melhor as possibilidades comunicacionais do criAtivo, incentivando-se, assim, uma participação mais efetiva.

Binômio 1: Olá "nome participante", participante da comunidade "nome da comunidade" do criAtivo. Você sabia que dentro da comunidade é possível interagir de várias maneiras?! Você tem a oportunidade de criar projetos, participar do fórum de discussões, enviar mensagens internas para os demais autores, participar do chat, dentre tantas outras possibilidades. Participe, interaja, comunique-se! Sua participação é extremamente importante para o projeto.

Para o segundo binômio da interatividade, que se refere à bidirecionalidadehibridização, será enviado um e-mail para os participantes da comunidade que possuem menor número de ações referentes a este binômio, conforme o que demonstra a tabela de monitoração das ações de cada indivíduo nas comunidades e o nível de interatividade que foi monitorado e representado pelo gráfico para o binômio 2 .

Neste caso, o e-mail pretende estimular estes indivíduos a participar do ambiente de forma mais colaborativa e interativa, onde todos possam ser potenciais emissores e receptores de informações. Para tanto é enviada a estes usuários a seguinte mensagem:

Binômio 2: Olá "nome participante", participante da comunidade "nome da comunidade" do criAtivo. Notamos que até o presente momento você tem participado pouco dos projetos da comunidade. Sabemos de seu interesse e destacamos a importância de sua participação. Assim, lhe convidamos a conhecer as ferramentas de suporte à comunicação, à participação, à interatividade e à colaboração. Dentre elas, destacamos: o fórum de discussão de cada comunidade. Aproveite esta oportunidade! Participe, interaja, comunique-se! Sua participação é extremamente importante para o projeto.

No que se refere ao último binômio da interatividade, que representa a potencialidade-permutabilidade, o e-mail enviado aos participantes da comunidade irá se referir aos participantes que não efetuaram ações de co-autoria, condição que pode ser identificada na tabela de monitoração que apresenta as ações que cada autor efetuou na 
10

comunidade, bem como pelo binômio 3 do gráfico da interatividade, que demonstra o nível de interatividade que foi monitorado.

Binômio 3: Olá "nome participante", participante da comunidade "nome da comunidade" do criAtivo. Verificamos que sua participação na comunidade não tem sido muito intensa, principalmente como co-autor de projetos. Sendo assim, gostaríamos de lembrá-lo que o criAtivo oferece recursos para que você possa se tornar um autor elou co-autor dos projetos. Dentre eles, destacamos: edição de momentos. Participe desta rede de interação! Assuma seu papel de autor e co-autor! Aproveite esta oportunidade!

Com estas ações de interação automatizadas junto aos participantes do criAtivo, pretende-se estimular a interatividade no ambiente, de forma que se possa alcançar, com isto, os objetivos propostos e estudados em cada binômio. Referente aos objetivos de cada binômio será apresentada a seguir uma interpretação do gráfico seguindo estes conceitos.

\subsection{Interpretando o gráfico segundo os binômios da interatividade}

Para um melhor entendimento do gráfico gerado a partir da monitoração da interatividade e do referencial teórico deste trabalho, descreve-se a seguir, quais os valores esperados para o gráfico.

Referente ao primeiro binômio, participação-intervenção, não se espera que os valores dos graus apresentados sejam elevados, pois este binômio está mais relacionado à participação do usuário no ambiente, onde participar nem sempre significa interagir e colaborar. Sendo assim, se no gráfico da interatividade o valor para o primeiro binômio for baixo, não significa que a interatividade não esteve presente no mesmo.

No que se refere ao binômio da bidirecionalidade-hibridização, o elemento principal é que o usuário seja um potencial emissor e receptor dentro das comunidades. Sendo assim, o grau esperado para este binômio é um grau mais elevado do que o do primeiro, pois várias ações que podem ser praticadas pelos participantes das comunidades, em um sentido de emissão e recepção de informação e conhecimento, estão enquadradas neste binômio.

Já o terceiro binômio da interatividade, potencialidade-permutabilidade, representa o maior nível de interatividade esperado entre os binômios, pois o mesmo se refere às possibilidades mais elevadas de participação, colaboração, interatividade e coautoria nos projetos. Por este binômio ser considerado o de maior importância seguindo as contextualizações teóricas e o uso do ambiente de uma maneira mais interativa, os graus esperados para ele são os mais elevados.

\section{Resultado da pesquisa}

Através das reflexões realizadas acerca dos elementos da Cibercultura e da Interatividade surgidas a partir da revisão bibliográfica, considera-se importante o desenvolvimento de mecanismo de monitoração para que se possam identificar elementos qualitativos referentes aos níveis de interatividade de comunidades, não somente no criAtivo, mas em ambientes virtuais de aprendizagem como um todo. 
11

Tal recurso auxiliará na identificação de dinâmicas de autoria que proporcionem aos usuários do ambiente romper com as barreiras de meros consumidores, para tornarem-se produtores, autores e co-autores, usando a tecnologia em beneficio próprio e coletivo. É necessário salientar que, futuramente, o processo de monitoração e interação automática com os usuários pode ser significativamente incrementado através da utilização de agentes.

Por fim, esta monitoração da interatividade traz aos ambientes virtuais de aprendizagem, como no caso do criAtivo, uma forma qualitativa de acompanhamento da interação com os usuários e a possibilidade de tornar automática ações de fomento à interatividade baseadas nos movimentos interativos efetivos das comunidades, liberando os agentes humanos envolvidos no processo desta tarefa.

\footnotetext{
${ }^{1}$ Mais informações sobre o criAtivo em: http://www.cinted.ufrgs.br/renote/dez2006/artigosrenote/25156.pdf Disponível em: http://inf.upf.br/criativo/criativo_testes
}

\section{Referências Bibliográficas}

Campos, Aline de. Ambiente Hipermídia de Autoria Colaborativa na Web: Construindo Alternativas de Inclusão Digital. 2006. Trabalho de Conclusão - Curso de Ciência da Computação da Universidade de Passo Fundo, Rio Grande do Sul, 2006.

Castells, Manuel. A sociedade em Rede. São Paulo: Paz e Terra, 2003.

Lemos, André; Cunha, Paulo (orgs). Olhares sobre a Cibercultura. Sulina, Porto Alegre, 2003.

Silva, Marco. Sala de aula interativa. 3.ed. Rio de Janeiro: Quartet, 2002.

Docência interativa presencial e online. In: VALENTINI, Carla Beatris; Soares, Eliana Maria do Sacramento. Aprendizagem em Ambientes Virtuais: Compartilhando idéias e construindo cenários. Caxias do Sul: EDUCS, 2005. p. 193202.

Teixeira, A. C. (2005) "Formação Docente e Inclusão Digital: a análise do processo de emersão tecnológica de professores”. Tese (Doutorado em Informática na Educação) - Programa de Pós Graduação em Informática na Educação da Universidade de Federal do Rio Grande do Sul, Rio Grande do Sul, 2005. 